\title{
Resistência e coexistência: da produção de mercadorias à valorização da vida
}

\author{
Resistance and coexistence: from the production of goods to the revolution of life \\ Resistencia y coexistencia: desde la producción de mercaderías hasta la valoración de la vida

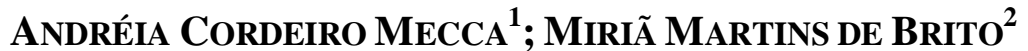 \\ Universidade FEDERAL de São Carlos, UFSCAR, São Carlos-SP, BraSIL
}

\begin{abstract}
RESUMO
O objetivo central deste ensaio foi discutir a diferença entre uma sociedade pautada na produção de mercadorias, que nega a fruição do ócio a favor do capital, e sociedades indígenas ameríndias, que valorizam a vida humana e dos demais seres. As raízes históricas do capitalismo foram base para reflexão de como a exploração do trabalho humano tornou-se o centro da busca por acumulação de riquezas. Depois abordamos visões de sociedades indígenas ameríndias que, desde uma filosofia ancestral em sintonia com a existência e a coexistência, respeitam a outrem e a Terra. Consideramos, com base na literatura escrita por indígenas, bem como de autores/as alinhados/as a referenciais suleados, a possibilidade de outro mundo possível, especialmente observando a filosofia do Bem-Viver, que aponta para a construção coletiva e harmônica de novas formas de viver, que valorizam e respeitam a diversidade, a natureza, a vida na Terra e da Terra.
\end{abstract}

Palavras-chave: Bem-Viver. Ócio. Trabalho.

\begin{abstract}
The purpose of this essay was to discuss the difference between a society based on the production of goods, which denies the enjoyment of leisure in favor of capital, and Amerindian indigenous societies, which value human life and that of other beings. The history of capitalism is the basis for reflecting on how the exploitation of human labor results in the accumulation of wealth. Then, we approach visions of indigenous Amerindian societies whose existence and coexistence respect each other and the Earth. We consider, based on the literature written by indigenous people, as well as authors aligned with southern references, another possible world, especially observing the philosophy of Good-Living and new ways of living, which value and respect diversity, nature, life on Earth and Earth.
\end{abstract}

Keywords: Good-Living. Idleness. Job.

\section{RESUMEN}

El objetivo principal de este ensayo fue discutir la diferencia entre una sociedad basada en la producción de mercaderías, que niega el disfrute del ocio a favor del capital, y las sociedades indígenas amerindias, que valoran la vida humana y la de otros seres. Las raíces históricas del capitalismo fueron la base para reflexionar sobre cómo la explotación del trabajo humano se convirtió en el centro de la búsqueda de la acumulación de riquezas. Después nos acercamos a visiones de sociedades indígenas amerindias que, desde una filosofía ancestral en sintonía con la existencia y la coexistencia, respetan a otren y a la Tierra. Consideramos, a partir de la literatura escrita por indígenas, así como de autores/as alineados con referenciales sureñados, la posibilidad de otro mundo posible, especialmente observando la filosofía del Buen-Vivir, que apunta a la construcción colectiva y armónica de nuevas formas de vivir, que valoran y respetan la diversidad, la naturaleza, la vida en la Tierra y en la Tierra. Palabras clave: Buen-Vivir. Ocio. Trabajo.

\footnotetext{
1 Doutoranda em Educação pelo Programa de Pós-Graduação em Educação da UFSCar. E-mail: andreia.mecca@gmail.com. ORCID: http://orcid.org/0000-0001-5703-4656.

2 Mestre em Educação pelo Programa de Pós-Graduação em Educação da UFSCar. E-mail: mihmartins23@hotmail.com. ORCID: http://orcid.org/0000-0001-8031-9705.
} 


\title{
TRABALHO COMO PROPOSTA DA SOCIEDADE CAPITALISTA
}

A revolução francesa de 1789 marcou, na história ocidental, o fim do feudalismo e início do sistema econômico burguês, o capitalismo. Porém, a transição entre esses dois sistemas é mais longa e ocorreu no decorrer de séculos, antes e depois desse marco. Também é preciso salientar que em muitas comunidades, na maioria originárias, o capitalismo não foi implementado, ainda que existam relações sociais e econômicas em alguns casos.

No sistema capitalista, a manufatura foi substituída pela máquina a vapor e depois pela eletricidade. Nesse processo, a relação entre empregador/e trabalhador/a modificou-se, ocorrendo intensa divisão do trabalho. Sendo assim, cada trabalhador/a assumiu um posto dentro do processo produtivo, ou seja, uma tarefa específica regida pelo tempo da máquina. Também se aprofundou a separação entre capitalista e trabalhador/a, cuja relação se deu em grande medida por aspectos econômicos, isto é, pela compra e venda da mão-de-obra. Outra importante característica é a produção em grandes escalas e no menor tempo possível. Segundo Marx (2010):

\begin{abstract}
Não é por o trabalho se tornar mais intenso ou por se prolongar a duração do processo de trabalho; nem é por o trabalho ganhar maior continuidade e, sob o olhar interessado do capitalista, mais ordem, etc., que se altera em si e para si o caráter do processo real do trabalho, do modo real do trabalho. Surge nisto, pois, um grande contraste com o modo de produção especificamente capitalista (trabalho em grande escala, etc., que, como indicamos, se desenvolve no decurso da produção capitalista e revoluciona não só as relações entre os diversos agentes da produção, mas também simultaneamente o caráter desse trabalho e a modalidade real do trabalho no seu conjunto [...] (p. 89).
\end{abstract}

Para aumentar a escala, foi necessário primeiro conquistar novos mercados e depois subtrair a demanda da produção. Os produtos, que antes eram feitos sob procura, passaram a ser fabricados continuamente, transmutando a centralidade da produção, que residia na necessidade do/a consumidor/a, para a mercadoria em si mesma. Portanto, a busca por novos mercados, em expansão com as grandes navegações, foi fundamental para o avanço desse sistema. De acordo com Marx e Engel (2007):

\begin{abstract}
A manufatura e, em geral, o movimento da produção experimentaram um enorme impulso graças à expansão do comércio ocorrida com a descoberta [invasão] da América e da rota marítima às Î́ndias Orientais. [...] enquanto as expedições de aventureiros, a colonização e sobretudo a expansão dos mercados até a formação de um mercado mundial - expansão que, então, se torna possível e realiza-se cada vez mais, dia após dia - despertam uma nova fase do desenvolvimento histórico [...]. Mediante a colonização dos países recém-descobertos [invadidos], a luta comercial entre as nações ganhou novo alinhamento e, nessa medida, uma extensão e uma animosidade maiores (p. 57).
\end{abstract}

A produção contínua e a inexistência de leis de proteção aos/às trabalhadores/as, tornou comum jornadas de trabalho de $12 \mathrm{~h}$ a $17 \mathrm{~h}$ horas, executadas tanto por adultos, quanto por crianças. Em alguns lugares, a jornada era tão extensa que as pessoas paravam apenas para dormir, o que poderia ocorrer na própria fábrica; também alguns padeciam em frente à máquina. Lafargue (1999) conta o caso da cidade de Mullhouse, no ano de 1838, onde trabalhadores/as moravam em habitações miseráveis, a milhas de distância do trabalho, com jornadas de $17 \mathrm{~h}$ e com período de alimentação de apenas 
1h30min. A redução da jornada e as leis de proteção aos/às trabalhadores/as só foram implementadas depois de séculos de lutas.

No capitalismo os burgueses detêm todos os meios de produção e os trabalhadores/as apenas sua própria capacidade de trabalho. Privados dos meios de produção, os/as operários/as também ficam privados/as dos meios de subsistência, o que os obriga à subordinação. A força de trabalho é, portanto, trocada por um salário, que muitas vezes compra exclusivamente a subsistência necessária para continuar trabalhando, como a energia que alimenta a máquina no processo produtivo.

Entretanto, essa troca é desigual, ou seja, o salário não representa o valor produzido pela força de trabalho, mas sim um valor menor (MARX, 2010). O prolongamento da utilização da força de trabalho para além do valor pago ao trabalhador/a é o que Marx (2010) chamou de mais-valia. Esse trabalho não pago, a mais-valia, é utilizada para saldar os custos da fábrica e gerar o lucro para o capitalista. Caso o/a trabalhador/a produzisse apenas o valor de seu salário, não haveria exploração nesse sistema. De acordo com Marx (2010):

[...] o dinheiro não pode transmutar-se em capital se não for trocado por capacidade de trabalho, enquanto mercadoria vendida pelo próprio operário. [...] De modo que o trabalho assalariado constitui uma condição necessária para a transformação de capital e se mantém como premissa necessária e permanente da produção capitalista (p.72-73).

A mais-valia pode ser adquirida de duas maneiras, prolongando a jornada e aumentando a intensidade da produção. O objetivo é que as mercadorias contenham o máximo possível de trabalho não pago e quanto mais mercadorias são produzidas, maior a mais-valia. Todavia, a realização desse valor só ocorre no momento em que o produto é vendido, exatamente por isso: "[...] não são as necessidades existentes que determinam o nível da produção, mas de que é a escala de produção - sempre crescente e imposta, por sua vez pelo próprio modo de produção - que determina a massa do produto" (MARX, 2010, p. 107-108).

\footnotetext{
No exageramos al afirmar que «[...] sin medias palabras, el capitalismo es un sistema de parásitos» (Bauman, 2010, p. 8), que focaliza su fuerza en el ingenio extraordinario y que busca, a través de la figura de las empresas, nuevos recursos cuando los anteriormente explorados se vuelven escasos, se agotan o se extinguen; y, también, en la fuerza del oportunismo y la rapidez dignos de un virus con la que se adapta a las nuevas condiciones y a la nueva realidad, calificada por el autor como nuevos pastos (LEMOS; GONÇALVES-JUNIOR; RODRIGUEZ-FERNÁNDEZ, 2020, p. 733).
}

A lógica ocidental dominante faz com que as pessoas acreditem que o nosso objetivo nesse mundo é trabalhar e produzir. Por causa dessa crença, estamos destruindo o planeta que vivemos, ampliando as desigualdades e nos tornando infelizes. Lafargue (1999) alertou: "Trabalhem, trabalhem, proletários, para aumentar a riqueza social e suas misérias individuais; trabalhem, trabalhem para que, ficando mais pobres, tenham mais razões para trabalhar e tornarem-se miseráveis" (p. 79).

Mulheres e homens, imersos nessa condição alienada do processo produtivo, fazem do trabalho o seu meio de vida, a própria crença em dias melhores, submetendose a essa lógica exploratória. Como alternativa à ideologia dominante, Lafargue (1999) vislumbra a possibilidade de retomada do ócio. Para isso seria necessário cessar a maisvalia e estabelecer jornadas curtas, cujo salário seria equivalente ao valor produzido. 
Dessa forma, as pessoas teriam tempo livre para se dedicar a outras atividades não produtivas.

Trabalho vem do Latim, Tripalium, que significa instrumento de tortura usado contra escravos e pobres, enquanto ócio veio do Latim otium, inatividade. Negócio, palavra comumente usada no capitalismo, significa a negação do ócio (CHAUÍ, 1999). $\mathrm{O}$ ócio, valorizado nas antigas sociedades gregas e romanas, e trabalho, que era executado somente por escravos e, portanto, motivo de desonra, tiveram seus significados invertidos na sociedade capitalista.

Antes as atividades artesanais eram, em muitos casos, realizadas na própria residência das pessoas, onde o tempo livre e o trabalhado não eram bem definidos, o que possibilitava a vivência do ócio e autonomia na administração do tempo. Com a chegada da indústria, o trabalho passa a ser realizado em local determinado, regido pelo ritmo da máquina. Como esse tempo é bem delimitado e pré-estabelecido, o ócio passou a ser negado, compreendido como sinônimo de preguiça e falta de vontade, muitas vezes inaceitável na vida adulta (GONÇALVES-JUNIOR; CORRÊA; RODRIGUEZFERNÁNDEZ, 2018).

\begin{abstract}
Así, el capitalismo incentiva solamente las actividades de la Industria del Ocio, involucradas con el propósito de controlar tanto el tiempo libre de las personas como la producción y consumo a gran escala de productos ideológicamente estimulados para las personas a través de una extraordinaria publicidad mediática y calificados como indispensables: la televisión táctil de última generación para la práctica y visionado de juegos deportivos; el viaje en paquete de «todo incluido» a modernos complejos turísticos; la adquisición de un novedoso aparato de musculación para la práctica de ejercicios físicos; la ropa con tejido transpirable para atletismo; o los videojuegos o los paseos por un centro comercial, entre otros (GONÇALVES-JUNIOR; CORRÊA; RODRIGUEZ-FERNÁNDEZ, 2018, p.129).
\end{abstract}

De acordo com Lafargue (1999), para romper com a lógica vigente seria necessário abrir caminhos para os "pecados" do ócio, pondo fim a esse sistema de exploração do trabalho. As bênçãos da preguiça são o gozo de uma vida boa, com tempo para o estudo e para as profundas reflexões acerca da cultura, da política, das ciências, das artes, de maneira que se possa fluir nas virtudes que fortalecem o espírito.

O ócio, portanto, seria o meio de lutar contra os privilégios de alguns pela "[...] apropriação da riqueza social e contra a barbárie contemporânea por que podem conhecê-la por dentro e aboli-la. Lutarão, não mais pelo direito ao trabalho, e sim pela distribuição social da riqueza e pelo direito de fruir de todos os seus bens e prazeres" (CHAUÍ, 1999, p. 56). A divisão social do trabalho realizada a partir da compreensão do valor do/a trabalhador/a, de acordo com Lafargue (1999), e de seu justo pagamento, possibilitaria a construção de uma sociedade mais justa e solidária. De acordo com Lemos, Gonçalves-Junior e Rodriguez-Fernández (2020):

Apreciar el mundo del ocio y del lúdico (retomando el canto, danza, juego y fiesta) puede estimular en las personas la necesidad de estrechar relaciones y practicar la solidaridad, la convivencia, la coexistencia, la corresponsabilidad y por el proyecto colectivo de vivir bonito de los pueblos del sur (p. 734).

O trabalho representaria o controle das forças da natureza para a satisfação de necessidades reais e também como forma de exteriorizar a capacidade humana, através de expressão criadora e inventiva (CHAUÍ, 1999). A atuação no mundo poderia ser construída com engajamento, tanto nas relações econômicas e políticas, quanto nas 
sociais e culturais. O trabalho realizado dessa forma seria prazeroso e implicaria no Bem-Viver de uma sociedade pautada por cidadãos e cidadãs livres da exploração que Lafargue (1999) chamou de trabalho assalariado.

\section{O BEM-VIVER COMO PROPOSTA ALTERNATIVA À SOCIEDADE CAPITALISTA}

A partir da análise dos/as autores/as acerca da estrutura da sociedade que estamos inseridos, compreendendo as raízes que sustentam a lógica capitalista e a relação de exploração do trabalho, apontamos para a centralidade que a acumulação de bens e riquezas ocupou em nossa sociedade. Até aqui, os anúncios apresentados por meio de Lafargue (1999), Chauí (1999), Lemos, Gonçalves-Junior e Rodriguez-Fernández (2020) e Gonçalves-Junior, Corrêa e Rodriguez-Fernández (2020) trouxeram alternativas para outro mundo possível, a partir de vivências imersas no capitalismo.

Todavia, outras cosmovisões coexistem nesse tempo e espaço e, desde a ancestralidade, constituem diferentes formas de viver e agir, por meio do respeito às diversas vidas e ao planeta. Essas cosmovisões podem nos trazer vivências distintas, bem como anunciar outros mundos possíveis, para além do que estamos pautando como alternativa. São sociedades que mantêm relações conscientes com o sistema capitalista e que podem contribuir com formas de luta e resistência.

As populações originárias da América Latina somam séculos de resistência ao genocídio, que continua ocorrendo de diversas formas, inclusive, por meio do Estado. Muitos embates foram travados com o intuito de dizimar esses povos e outros tantos os quiseram catequizar, negar e invisibilizar seus costumes, tradições, línguas, modos de ser e estar no mundo, ou seja, "[...] transformá-los em civilizados que poderiam integrar o clube da humanidade" (KRENAK, 2020, p. 14). Ainda hoje a resistência perpassa o existir, a visibilidade, a afirmação da presença:

\footnotetext{
Eu falei: 'Tem quinhentos anos que os índios estão resistindo, eu estou preocupado é com os brancos, como que vão fazer para escapar dessa'. A gente resistiu expandindo a nossa subjetividade, não aceitando essa ideia de que nós somos todos iguais. Ainda existem aproximadamente 250 etnias que querem ser diferentes umas das outras no Brasil, que falam mais de 150 línguas e dialetos (KRENAK, 2019, p. 15).
}

Krenak (2020) alerta para a compreensão do real sentido do que é ser humano. A ideia naturalizada de que somos pertencentes a um clube chamado de humanidade, nos coloca sob as mesmas regras ideológicas e sociais. A concepção de humanidade exclui $70 \%$ das pessoas, aliena os/as humanos/as da natureza, invisibilizando a diversidade de raízes, costumes, tradições e línguas. Nas palavras de Krenak (2020):

\footnotetext{
Esse pacote chamado de humanidade vai sendo descolado de maneira absoluta desse organismo que é a Terra, vivendo numa abstração civilizatória, que suprime a diversidade, nega a pluralidade das formas de vida, de existência e de hábitos. [...] Fomos muito tempo embalados nessa história de que somos a humanidade e nos alienamos desse organismo de que somos parte, a Terra, passando a pensar que ele é uma coisa e nós, outra: a Terra e a humanidade (p. 7-8).
}

A humanidade, consubstanciada na globalização e nas práticas de grandes multinacionais, também recria espaços ao redor do planeta. Cidades como São Paulo, Nova York ou Paris são bem parecidas e contêm as mesmas gamas de produtos 
capitalistas. Nessas cidades verticais, com túneis de metrô, rios canalizados, impermeabilização do solo, entre outros aspectos, fica quase impossível tocar os pés na terra. As cidades de pedra afastam a natureza viva dos arredores: animais, pássaros, árvores e plantas, que ficam também privados das formas originais de vida. Por esse e outros motivos é que os humanos estão segregados da natureza e a vislumbram como algo distante e inanimado. De acordo com Kopenawa e Albert (2019):

\begin{abstract}
Nessa cidade de Paris, multidões de carros e ônibus corriam o dia todo, fazendo um barulho ensurdecedor, apertados no meio das casas. A terra de lá é toda escavada de túneis sem fim, como se fossem de grandes minhocas. Longos trens de metal não paravam de andar por eles com grande estrondo, deslizando em barras de ferro há muito arrancadas das profundezas do chão. É também por isso que me parecia que o chão tremia o tempo todo, mesmo durante a noite. Para quem sempre dormiu no silêncio da floresta, essas vibrações são muito inquietantes. Os brancos não parecem percebê-las, porque estão acostumados a nunca deixar sua terra em paz. Mas eu não parava de pensar que ela devia virar outra por causa do barulho e da agitação que a maltratavam sem trégua. Por isso virei fantasma tantas vezes durante aquela viagem! (p. 423).
\end{abstract}

Um dos grandes desafios é superar a lógica do consumismo e do produtivismo, que usurpa da natureza e explora a força de trabalho de mulheres e homens. A concepção de apropriação, acumulação e de posse dos bens, isto é, das "coisas" são as bases do sistema capitalista, acerca disso, Tabajara (2018a) escreve: "[...] e assim pude perceber, tudo aqui tem um padrão: Quem tem grana é patrão; o ter é mais que o ser" (p. 32). Diferente dessa concepção, para povos originários o que existe é uma relação de desapego das mercadorias, atribuindo valor a partir da utilidade e do compartilhamento, Tabajara (2018b) escreve: “[...] na aldeia tudo é arte, tudo também se reparte” (p. 65). Segundo Kopenawa e Albert (2019):

Esse é o nosso costume, tanto com os objetos que fabricamos como com as
mercadorias que nos vêm dos brancos. [...] Nenhum de nós deseja suas
mercadorias só para empilhá-las em casa e vê-las ficando velhas e
empoeiradas! Ao contrário, não paramos de trocá-las entre nós, para que
nunca se detenham em suas jornadas. São os brancos que são sovinas e fazem
as pessoas sofrerem no trabalho para estender suas cidades e juntar
mercadorias, não nós! Para eles, essas coisas são mesmo como namoradas!
Seu pensamento está tão preso a elas que se as estragam quando ainda são
novas ficam com raiva a ponto de chorar! São de fato apaixonados por elas!
[...]. Nós não somos como eles. Mais do que nos objetos que queremos
possuir, é nos xapiri [espíritos] que nosso pensamento fica concentrado, pois
só eles são capazes de proteger nossa terra e de afastar para longe de nós tudo
o que é perigoso. Se os brancos pudessem, como nós, escutar outras palavras
que não as da mercadoria, saberiam ser generosos e seriam menos hostis
conosco. Também não teriam tanta gana de comer nossa floresta (p. 413-
414).

Acosta (2016) nos traz outros mundos possíveis a partir da concepção do BemViver, ou seja, da busca por alternativas para construção coletiva de novas formas de viver, que não ignoram a diversidade e respeitam todos os seres vivos. Outro mundo é possível se for pensado e organizado em conjunto, considerando os Direitos Humanos e os Direitos da Natureza, bem como construindo relações respeitosas e conscientes nos âmbitos políticos, econômicos, culturais e ambientais. De acordo com Brandão (2005): "[...] podemos aprender a nos constituir, livres de toda coerção e de toda propaganda 
criadora de falsos desejos, falsos direitos e falsos deveres, como critérios do que de fato necessitamos para viver" (p. 67).

Nesse sentido, o Bem-Viver se relaciona com as tradições indígenas, ao mesmo tempo em que critica os socialismos antropocêntricos e toda forma de autoritarismo. Ao contrário, busca a transformação a favor de visões sociobiocêntricas, em que o BemViver e os Direitos da Natureza estão presentes. Para tanto, é necessário a construção de "[...] uma sociedade que entenda que faz parte da Natureza e que deve conviver em harmonia com ela e dentro dela" (ACOSTA, 2016, p. 133). Kambeba (2020) complementa:

A natureza é mãe e nos alimenta, por isso, há por parte das populações indígenas e dos que vivem às margens dos rios uma preocupação quanto ao tratamento que se está dando a esse recurso precioso a humanidade. Pensar a natureza de forma sustentável é uma prática há séculos executada pelos povos da terra (p. 62).

Conforme Guajajara (2020), é necessário compreendermos que o meio ambiente e as lutas sociais não são dissociados. As terras indígenas são os territórios mais preservados do país, porém quem as protegem não são as políticas ambientais, mas sim os povos que as ocupam. A maneira de viver dos povos indígenas e a forma como se relacionam com o meio ambiente e com as comunidades tradicionais, garantem a proteção desses territórios. A autora destaca:

O que a gente faz beneficia todas as pessoas. Não é uma "luta de índio", mas uma luta pelo planeta. É bem importante as pessoas saberem que nós, indígenas, somos $5 \%$ da população mundial e conseguimos proteger com o nosso modo de vida próprio $82 \%$ da biodiversidade que existe ainda viva no planeta. Por isso a luta tem que ser compreendida e abraçada por todo mundo, pois, se não há biodiversidade, não há vida no planeta [...]. (GUAJAJARA, 2020, n.p.).

Dessa forma, a expressão da presença indígena, em seu modo de viver, pode contribuir com mudanças no corpo da coletividade, pois nessas visões "[...] tudo está em harmonia com tudo, tudo está em tudo e cada um é responsável por essa harmonia" (MUNDURUKU, 2019, p. 33). Essa forma de viver expõe que em diferentes culturas, todos os seres vivos têm o direito de nascer e vivenciar experiências de vida cada vez mais livres de controles sociais (PENZANI, 2019).

O Bem Viver, tal qual no conceito em construção apresentado por Alberto Acosta, refere-se, portanto, à vida em pequena escala, sustentável e equilibrada, como meio necessário para garantir uma vida digna para todos e a própria sobrevivência da espécie humana e do planeta. $O$ fundamento são as relações de produção autônomas, renováveis e autossuficientes. O Bem Viver também se expressa na articulação política da vida, no fortalecimento de relações comunitárias e solidá- rias, assembleias circulares, espaços comuns de sociabilização, parques, jardins e hortas urbanas, cooperativas de produção e consumo consciente, comércio justo, trabalho colaborativo e nas mais diversas formas do viver coletivo, com diversidade e respeito ao próximo (TURINO, 2016, p. 15-16).

Nessas sociedades a natureza não está a serviço dos/as humanos/as, pois não há dicotomia, somos natureza. Dessa forma, a busca por lucro torna-se insensata, pois se estamos integrados, a exploração e a destruição dos recursos naturais, empreendidos na produção permanente de mercadorias, nos atinge na mesma proporção. O respeito à vida 
neste planeta envolve o bem-estar humano, portanto, nosso objetivo não deve ser apenas o trabalho e a produção de bens.

\begin{abstract}
Neste ponto, é substancial uma diferenciação entre a produção para a criação de um excedente e a produção voltada ao sustento da vida. Seguindo o modelo interpretativo sobre a economia doméstica, as sociedades cultivadoras de floresta valorizam e praticam a segunda forma, em detrimento da primeira. Seria adequado interpretar como 'miséria' em uma sociedade a suspensão das atividades produtivas exatamente no ponto em que a estabilidade social está garantida? (SOUZA, 2002, p. 240).
\end{abstract}

Dentro dessa visão, a produção tem como objetivo a exclusiva satisfação das necessidades. Não há um local e um tempo definidos para o trabalho, o que deixa livre a gestão do ócio. São formas plurais que compreendem que a vida neste planeta é uma dádiva e deve ser coroada com sabedoria, solidariedade e diversão.

No geral, as sociedades cultivadoras de floresta são voltadas para o ócio, reservando largo tempo para festejos e repousos; a atividade produtiva é interrompida constantemente por outras atividades não-produtivas (cerimônias, diversões, sociabilidade e repouso). O próprio trabalho, como já se viu, possui um sentido também lúdico (SOUZA, 2002, p. 243).

O centro das vivências não é produção ininterrupta de mercadorias a todo custo (social, cultural, ambiental, entre outros), mas sim os seres-natureza, que con-vivem em manifestações plurais da vida no planeta. Há centenas de povos vivos, com narrativas diversas da sociedade capitalista, o que torna ainda mais necessário ampliar o horizonte acerca de concepções arraigadas sobre a humanidade, a natureza, o trabalho e o ócio.

\title{
ANÚNCIOS PARA UM NOVO MUNDO POSSÍVEL
}

Compreender a lógica que sustenta a sociedade capitalista leva à afirmação de que a degradação social e ambiental é estrategicamente mantida através da exploração da força do trabalho. Lafargue (1999) anuncia que o despertar consciente dos/as operários/as será possível quando estes, reconhecendo sua força, reivindicarem a diminuição da jornada de trabalho, construindo um mundo em que trabalhadores/as gozem dos prazeres do ócio.

No mesmo sentido, Marx e Engels (2010) anunciaram "PROLETÁRIOS DE TODOS OS PAÍSES, UNI-VOS!” (p. 68). Os autores não acreditavam que jornadas menores poderiam melhorar a situação da classe trabalhadora, pois mesmo com jornadas reduzidas, seria possível manter a exploração. Somente a revolução proletária traria horizontes de mudanças e transformações. Marx e Engels (2010) propuseram o fim do capitalismo e a constituição de um novo sistema, o comunismo, do qual não se detiveram, apenas indicaram.

Para Brandão (2005), os primeiros passos da transformação "[...] são tanto de ordem política, e incidem sobre a estrutura do poder globalizado que nos domina, quanto de ordem pessoal e interativamente interior. Reflexiva. Uma nova ordem de trocas entre as pessoas e entre elas e a Vida" (BRANDÃO, 2005, p. 67).

Podemos retirar da economia de mercado a nossa procura de soluções, em direção a uma economia francamente solidária. Não precisamos de tanto; não precisamos consumir tanto para viver; não precisamos aspirar tantas coisas para sermos felizes. Precisamos de olhos de mãos e de ternura; precisamos 
menos de patrões e de mandatários e precisamos mais de companheiros de destino (BRANDÃO, 2005, p. 65).

Acosta (2016) considera o Bem-Viver uma estratégia coletiva para um projeto de vida para todos e todas, com a possibilidade de conceber espaços de poder real, como efetivos poderes de ação democrática em contexto político, econômico e cultural. A ideia, conforme o autor, é ir gerando nesses espaços "[...] embriões de uma nova institucionalidade estatal, de uma renovada lógica de mercado e de uma nova convivência social" (ACOSTA, 2016, p. 168).

Para nós, a constituição de outro mundo deve ser assumida por mulheres e homens em suas relações não apenas com o trabalho, mas com todos os demais seres vivos. Além de outra economia, serão necessárias práticas distintas do que foram estruturadas pelo capitalismo, cujas ações levem em consideração todos os aspectos de uma vida em comunidade, isto é, inclusiva, harmônica e respeitosa. Princípios como justiça, solidariedade e equidade devem guiar essa nova maneira de viver.

Dentre tantos desafios, a busca por novas formas de viver, consiste em se posicionar criticamente diante do sistema dominante. Portanto, refletir sobre os limites e incongruências pode contribuir para a realização de um mundo melhor. Por meio dos diferentes saberes podemos buscar a ampliação de propostas, chegando a novos horizontes. Nesse sentido, as diversas vozes, como aquelas vindas de povos indígenas e de tantas outras minorias produzidas por esse sistema, ao gritarem juntas podem criar propostas inovadoras de ser e estar no mundo.

A busca por essa revolução da vida pode parecer utópica, mas quanto a isso Brandão (2005) ressalta que é necessário sonhar e ter coragem, sair de uma atitude de negação da vida para compromisso com ela. Retomar a arte de sonhar é necessário, pois habitar o sonho é abrir espaço para "[...] uma experiência transcendente na qual o casulo humano implode, se abrindo para outras visões da vida não limitada" (KRENAK, 2019, p. 32). Sendo assim, sonhar é enxergar possibilidades de intervenções na estrutura do sistema capitalista, como brechas para empreender novos fluxos.

As reflexões até aqui apresentadas nos provocam a refletir acerca das mudanças que queremos em nossa sociedade, para além de denúncias superficiais sobre a estrutura capitalista. Assim, a resistência está imbricada em ações coletivas e individuais que abrangem outras formas de viver e que desafiam o sistema vigente ao apresentarem alternativas de vida. A coexistência dessas possibilidades pode levar à transformação das relações e à valorização da vida e dos demais seres vivos, isto é, à construção de um mundo melhor, mais justo, integrado e solidário.

\section{REFERÊNCIAS}

ACOSTA, A. O bem viver: uma oportunidade para imaginar outros mundos. São Paulo: Autonomia Literária, 2016.

BRANDÃO, C. R. Qualidade de Vida, vida de qualidade e qualidade da vida. In: BRANDÃO, C. R. A canção das sete cores: educando para a paz. São Paulo: Contexto, 2005. p. 27-72.

CHAUÍ, M. Introdução. In: LAFARGUE, P. O direito à preguiça. São Paulo: Hucitec/Unesp, 1999. p. 09-56.

GONÇALVES JUNIOR, L; CORRÊA, D. A.; RODRIGUEZ-FERNÁNDEZ, J. E. Vivencia del ocio entre hombres: los juegos de bocha (São Paulo, Brasil) y bolos tradicionales (Boiro, España). Retos, v. 33, n. 1, p. 129-133, 2018. 
GUAJAJARA, S. Governo Bolsonaro é o retrato da barbárie contra indígenas, por Sônia Guajajara. Jornal GGN, 18 abr. 2020. (não paginado). Disponível em: https://jornalggn.com.br/politicassociais/governo-bolsonaro-e-o-retrato-da-barbarie-contra-indigenas-por-sonia-guajajara/. Acesso em: 19 nov. 2020.

KAMBEBA, M. W. O lugar do saber. São Leopoldo: Casa Leiria, 2020.

KOPENAWA, D.; ALBERT, B. A queda do céu: palavras de um xamã yanomani. 6. reimp. São Paulo: Cia. das Letras, 2019.

KRENAK, A. O amanhã não está à venda. São Paulo: Companhia das Letras, 2020.

KRENAK, A. Ideias para adiar o fim do mundo. São Paulo: Companhia das Letras, 2019.

LAFARGUE, P. O direito à preguiça. São Paulo: Hucitec/Unesp, 1999.

LEMOS, F. R. M.; GONÇALVES JUNIOR, L.; RODRIGUEZ-FERNÁNDEZ, J. E. Praxis con ociomotricidad: procesos educativos movilizados con estudiantes de pregrado en Educación Física del interior de São Paulo, Brasil. Retos, v. 38, n. 1, p. 129-133, 2020.

MARX, K. Capítulo VI inédito de o capital, resultados do processo de produção imediata. 2. ed. São Paulo: Centauro Editora, 2010.

MARX, K.; ENGELS; F. Manifesto comunista. São Paulo: Boitempo, 2010.

MARX, K.; ENGELS; F. A ideologia alemã. São Paulo: Boitempo, 2007.

MUNDURUKU, D. Das coisas que aprendi: ensaios sobre o bem-viver. Lorena: Uk'a, 2019.

PENZANI, R. O que as crianças aprendem ficando presas? A fugir. Lunetas, 02 maio 2019. Disponível em: https://lunetas.com.br/ailton-krenak. Acesso em: 19 nov. 2020.

SOUZA, J. O. C. O sistema econômico nas sociedades indígenas Guarani pré-coloniais. Horizontes Antropológicos, Porto Alegre, v. 8, n. 18, p. 211-253, 2002.

TABAJARA, A. Coração na aldeia, pés no mundo. Lorena: Uk’a, 2018a.

TABAJARA, A. O grão. Revista do Instituto Humanitas Unisinos, v. 527, n. 1, p. 62-66, 2018 b.

TURINO, C. Prefácio à edição brasileira. In: ACOSTA, A. O bem viver: uma oportunidade para imaginar outros mundos. São Paulo: Autonomia Literária, 2016. p. 13-16.

Recebido em: 30 nov. 2020.

Aprovado em: 16 abr. 2021. 